\title{
2006-196: INTERDISCIPLINARY COLLABORATION IN AN INTRODUCTORY BIOENGINEERING COURSE
}

\section{Laura Sullivan, Kettering University}

Dr. Laura Sullivan arrived at Kettering University in 1992, after completing M. S. and Ph. D. degrees in Materials Science and Engineering at the University of Texas at Arlington. Prior to this, she obtained a B.S. degree in Biomedical Engineering from Arizona State University and worked as a Clinical Orthopedic Engineer for the Baylor College of Medicine in Houston, Texas. With expertise in polymer engineering and biomaterials, Professor Sullivan has taught Mechanics, Engineering Materials, Polymer Processing, Polymer Properties, and Biomaterials at Kettering University. From 1999-2002, she also served as Associate Dean of Student Affairs at Kettering. Dr. Sullivan has served as Division Chair and Program Chair for the Materials Division of ASEE, and she is also a member of the Women In Engineering Division. In addition to ASEE, she maintains membership in the Society of Women Engineers and is a member of the Women in Engineering Leadership Institute.

\section{Patrick Atkinson, Kettering University}

Dr. Atkinson is an Associate Professor in Kettering University's Mechanical Engineering Department and the Orthopaedic Research Director at McLaren Regional Medical Center. His research interests include orthopaedic biomechanics of the hip and knee, and injuries suffered by occupants during automotive accidents. He regularly publishes in the orthopaedic, biomechanics, and automotive safety journals and presents his work at national conferences.

\section{Stacy Seeley, Kettering University}




\section{Interdisciplinary Collaboration in an Introductory Bioengineering Course}

The Interdisciplinary course discussed in this paper is taught under the supervision of the Mechanical Engineering department at a university that focuses primarily on undergraduate engineering. Of the 2400 undergraduate students attending this university, roughly 1500 of these students are student are studying Mechanical Engineering.

These Mechanical Engineering students are given the opportunity to declare a "concentration" within the degree program by selecting a pre-specified group of technical and free electives. Because the university has faculty with expertise in automotive engineering and valuable automotive engineering resources, two of the concentrations that have always been favorites among students are "Automotive Body and Chassis" and "Automotive Powertrain". The next most popular concentration among ME students, chosen by $37 \%$ of students who select a concentration, is the Bioengineering Application". This specialty grew from a series of courses first developed by faculty specializing in automotive crash safety and orthopedic biomechanics. A sense that these courses were attracting students already at the university, and that they had the potential to recruit high school students (especially underrepresented minorities) became the impetus for developing a concentration. Currently, the Bioengineering Application concentration includes the following:

Introduction to Bioengineering Applications

Choose three of the following five:

Biology I

Biology II

Anatomy and Physiology

Automotive Bioengineering: Occupant Protection and Safety

Vehicular Crash Dynamics and Accident Reconstruction

Bioengineering Applications Project (Capstone)

This paper focuses on the Introduction to Bioengineering Applications course. While the majority of students who enroll in this course have selected the Bioengineering Application concentration (90\% in the winter of 2006), this is not a requirement for enrollment. Prerequisites for the course are Organic Chemistry (for the Biochemistry topics covered) and Solid Mechanics (for the Biomechanics topics covered). The course is taught during the winter and spring terms each year. In 2006, the enrollment for the year will be 80 students.

Introduction to Bioengineering Applications is team taught by three faculty members from two departments, each teaching approximately one third of the course curriculum. The first third of the course is facilitated by a Chemistry professor in the Science and Mathematics department, who combines topics on biochemistry with lectures on the cells and tissue. Systems discussions begin in this rotation with the nervous system and the cardiovascular system. The second third of the course is taught by a Mechanics professor in the Mechanical Engineering department, who applies his expertise in orthopedics and crash safety to facilitate the study of muscle and skeletal biomechanics. During this rotation, the students also participate in interactive orthopedic labs, including a casting lab, observation of surgical procedures, and interaction with orthopedic 
research residents at local hospitals. The final third of the course is taught by a Materials professor in the Mechanical Engineering department, who combines information on the lymphatic and immune system with biomaterials lectures. This rotation begins with a biomaterials discussion, focusing on the mechanical and chemical characteristics of metals, polymers, and ceramics currently used in implant applications.

At the beginning of the term, students are encouraged to gain exposure to journal articles via PubMed as they are assigned (in teams) a set of metallic, polymeric, and ceramic materials to assess for biocompatibility. When they reach the final third of the course and have begun to discuss the immune system and biomaterials, this topic is revisited. An example of this assignment is included here:

\section{Objective: Select an appropriate material for use in the full joint replacement of the first metatarsophalangeal (MTP) joint (also known as the big toe).}

Degenerative joint disease of the big toe joint has been called by many names: Hallux Rigidus, severe Hallux Limitus, late or end stage arthrosis, Hallux Flexus, dorsal bunion, arthritis of the big toe, Gout, enchondrosis, chondro-malacia. This degerative condition of the big toe falls under the category of osteoarthritis. Xrays would reveal a decreased joint space and deformity of the bone.

Considering the wear that this implant is subjected to during walking, and the exposure of the implant to living tissue, determine which of the materials you have been assigned would be appropriate from which to manufacture an MTP implant. Since this implant is subjected to wear, you should consider the possibility that particles of your material will end up in the surrounding tissue. This material could travel via the bloodstream or lymphatic vessels to major organs.

You need not be concerned with the strength or stiffness requirements of this implant, nor do you need to worry about the how easy or difficult this implant would be to manufacture. Simply concern yourselves with the toxicity of the materials.

Attached, you will find a spreadsheet listing the metal, polymer and ceramic that your group has been assigned. As a group, comment on the toxicity of each material, entering your comments into this spreadsheet. Include in your discussion the acute vs. chronic toxicity, and any cytotoxic, genotoxic, or carcinogenic characteristics of the materials.

After the discussion of biomaterials during the third rotation, and yet while the topics of toxicity are fresh, a discussion of the lymphatic and immune system completes the course. As an alternate method of assessing student learning for this final topic students are asked to create educational comic books that describe the function of the lymphatic system, including a very detailed list of components, to fourth grade readers. We know that some students are better at synthesizing and applying information than they are at storing it. We believe that this exercise 
better assesses learning in students who do poorly on tests that require them to memorize a set of vocabulary words.

Each team of students created a Lymphatic System Comic Book that explained a list of topics similar to the following:

- Lymph, interstitial fluid, and blood

- Arterial capillaries, venous capillaries, and lymphatic capillaries

- Lymph nodes and lymphatic nodules

- Spleen, Red bone marrow, and Thymus

- Helper T-cells, Killer T-cells, and Memory T-cells

- B-cells

- Macrophages

- Antigen presenting cells

- Skeletal and Respiratory pumps

- MHC proteins

Our students appreciated not having to memorize the lymphatic system vocabulary, and they were pleasantly surprised by their own creativity. Assessment of the comic books was based upon how clearly each of the topics was presented to a panel of three fourth graders and one teacher. Almost all of the comic books were assessed at a high level.

Student evaluations of this course have been positive, and course enrollment has grown every year, indicating positive student feedback. The criticism that we deal with most often is that the breadth of material is too great for the length of the course. We are currently reevaluating the syllabus to eliminate portions of the course that are not (a) most useful in subsequent courses in the concentration or (b) most beneficial to students' goals in research or medical training. 